International Journal of Current Advanced Research

ISSN: O: 2319-6475, ISSN: P: 2319 - 6505, Impact Factor: SJIF: 5.995

Available Online at www.journalijcar.org

Volume 6; Issue 4; April 2017; Page No. 3045-3047

DOI: http://dx.doi.org/10.24327/ijcar.2017.3047.0176

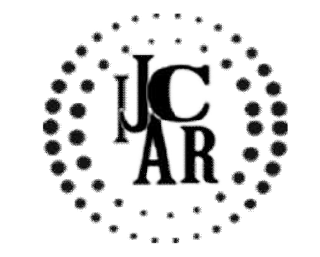

Research Article

\title{
CAD/CAM IN PROSTHODONTICS: AN ERA OF DIGITAL DENTISTRY
}

\section{Prema Sivakumar* and Preetham Prasad Nittla}

Department of Prosthodontics, Saveetha Dental College

\begin{tabular}{l} 
A R T I C L E I N F O \\
\hline Article History: \\
Received $11^{\text {th }}$ January, 2017 \\
Received in revised form $19^{\text {th }}$ February, 2017 \\
Accepted $22^{\text {nd }}$ March, 2017 \\
Published online $28^{\text {th }}$ April, 2017
\end{tabular}

Key words:

$\mathrm{CAD} / \mathrm{CAM}$, materials used, history, applications

\begin{abstract}
A B S T R A C T
$\mathrm{CAD} / \mathrm{CAM}$ (computer-aided design and computer-aided manufacturing) is being increasingly used to improve the design and creation of dental restorations, especially dental prostheses, including crowns, crown lays, veneers, inlays and onlays, fixed bridges, dental implant restorations, dentures (removable or fixed), and orthodontic appliances. $\mathrm{CAD} / \mathrm{CAM}$ increases the speed of design and creation, the convenience or simplicity of the design, creation, and insertion processes and makes possible restorations and appliances that otherwise would have been infeasible. This revolutionary technology has facilitated chair side dentistry, where the restorations are fabricated in the same sitting, increasing the efficiency and quality of the dental practice.
\end{abstract}

Copyright $₫ 2017$ Prema Sivakumar et al. This is an open access article distributed under the Creative Commons Attribution License, which permits unrestricted use, distribution, and reproduction in any medium, provided the original work is properly cited.

\section{INTRODUCTION}

The latest innovations in TECHNOLOGY made almost all things possible. High quality dental devices can routinely be fabricated through the collaboration of dentist and dental technicians. As dentistry evolves into the digital world of image capture, computer design, and the creation of dental restorations through robotics, the dental laboratory must evolve as well. All Computer-aided design/Computer-aided manufacturing (CAD/CAM) systems consist of three components:

1. A digitalisation tool/scanner that transforms geometry into digital data that can be processed by the computer

2. Software that processes data and, depending on the application, produces a data set for the product to be fabricated

3. A production technology that transforms the data set into the desired product. [1] CAD/CAM may also reduce the fabrication time of high strength ceramics by up to $90 \%$ [2].

\section{History of $\mathrm{Cad} / \mathrm{Cam}$}

Though computer-aided design/computer- aided manufacturing (CAD/CAM) for dentistry has been available for the past 25-30 years, it's only been within the past decade that the technology has moved from the lab to chairside. Much like radiovisiography technology, dental CAD/CAM technology got its start in Europe in the 1970s and 1980s.

*Corresponding author: Prema Sivakumar

Department of Prosthodontics, Saveetha Dental College
However, early versions of $\mathrm{CAD} / \mathrm{CAM}$ systems were so cumbersome and complicated that they were considered more of a hindrance and confined to the laboratories alone. Research and development of dental CAD/CAM systems has been actively pursued world-wide since $1980^{\circ e} \mathrm{~s}$ due to continuous efforts of three pioneers namely, Dr. Francois Duret, Dr. Werner Mormann and Dr. Andersson.[2] Dr. Duret was the first to develop dental CAD/CAM.[3] From 1971, he began to fabricate crowns with an optical impression of abutment followed by designing and milling. Later he developed Sopha system. Dr. Mormann developed CEREC System, an innovative approach to fabricate same day restorations at the chair side in the dental office.[4] Dr. Anderson developed Procera System[5] He attempted to fabricate titanium copings by spark erosion and introduced $\mathrm{CAD} / \mathrm{CAM}$ technology into the process of composite veneered restorations.[6] This system later developed as a processing center networked with satellite digitizers around the world for the fabrication of all ceramic frameworks. [714] CAD/CAM initially started out as a system with single axis for milling, it has developed into systems with multiple axes for a faster and more accurate result.

\section{The Process}

The first stage is the Computer surface digitization. This technique can be broadly divided into two categories:

1. Mechanical scanning devices.

2. Optical scanning devices.

Optical camera, LASER surface scanning device, three dimensional (3-D) scanning device (digitizer), photogrammetry, Moiré fringe displacement, computed tomography (CT-Scan), magnetic resonance imaging (MRI), 
3-D ultrasonography etc. are some of the technologies used for computer surface digitization.

The next stage in $\mathrm{CAD} / \mathrm{CAM}$ is Computer-aided designing (CAD). Once the 3-D image is captured through any of the computer surface digitization techniques, 3-D image processing is done and the digitized data is entered in the computer. Finally, curve smoothening, data reduction and blocking of undercuts can be done at this stage. Designing of the restoration is done using CAD software, which in turn send commands to the CAM unit, for fabricating the restoration.

Third and the final stage is Computer-aided manufacturing (CAM). In this stage the milling is done with computerized electrically driven diamond disks or burs which cut the restoration from ingots. This process is commonly known as "substractive method".

Other CAM methods are "additive", for example rapid prototyping or selective laser sintering. Here, material wastage can be prevented since there is no remaining excess material. Some CAD/CAM systems have been developed which utilize a combination of these two methods (additive and substractive methods).

\section{Applications of CAD/CAM}

\section{CAD/CAM technology in removable partial denture prostheses}

Fabrication of cast partial dentures can be done using $\mathrm{Co}-\mathrm{Cr}$ Alloys or commercially pure Titanium and Ti-6Al-4V Alloy by utilizing CAD-CAM technologies.

William et al have demonstrated a method of fabrication of removable partial denture framework design using $\mathrm{CAD} / \mathrm{CAM}$ technologies. Using $\mathrm{CAD} / \mathrm{CAM}$ software the removable partial denture framework design is built on a three-dimensional scan of the patient's cast.[15, 16]

\section{CAD/CAM technology in fixed prosthodontics}

CEREC in Lab system - The tooth preparation die is secured in the scanning platform and data is captured with a noncontact laser. A Ceramic block (ingot) is placed in the milling chamber. Two milling diamonds create the precise restoration. Porcelain build-up is done which results in an aesthetically pleasing restoration. Then the fit is confirmed in the patient's mouth and required adjustments are done.

\section{CAD/CAM technology in maxillofacial prosthodontics}

$\mathrm{CAD} / \mathrm{CAM}$ is widely used for the fabrication of maxillofacial prostheses, extraoral radiation devices, individual respiratory masks and facial protection devices etc.

Three dimensional surfaces imaging is done by using CAD software. This 3-D surface image aids in the fabrication of resin model with Lithographic technique and then waxpattern is made. Of this completed wax pattern, once again computer assisted three dimensional imaging is done. Data is entered in computer and prosthesis is milled by computer aided milling machine. Thus, a silicone maxillofacial prosthesis is fabricated using $\mathrm{CAD} / \mathrm{CAM}$ technology.

\section{CAD/CAM technology in fabrication of surgical guides for implant placement}

Bibb et al described the fabrication of stainless steel surgical guides for the placement of dental implants for prosthetic retention using SLM technology. It was first reported for the manufacture of custom-fitting surgical guides.[17]

\section{CAD/CAM technology in implant prosthodontics}

Computer usage in implant placement (Navigational technique) has increased in the past decade. Recently with the use of $\mathrm{CAD} / \mathrm{CAM}$ application patient-specific abutments can be fabricated. These CAD/CAM fabricated custom abutments are designed by computer and manufactured by computer operated machines for obtaining unsurpassed accuracy and precision. As they are milled from medical-grade Titanium, they have superior biocompatibility and best possible integration with implant fixture.The CAD/CAM fabricated custom abutments carries advantages like: - precision, milled from titanium, ideal coronal preparation, correct path of insertion, perfect emergence profile, $6^{\circ}$ angled implant axis, shaped like a natural tooth and reduced chair time.

Computerized designing of abutment is done and primary abutment is fabricated from commercially pure titanium via computerized-milling technique. Another duplicate abutment is milled, which is functionally identical to primary abutment, thus reducing chair time.[18]

Advantages of CAD/CAM system

- No Traditional Impressions.

- High Precision and Accuracy.

- Eliminates the Use of the Laboratory Equipments

- Improvedrestoration quality.

- Reduced appointment time

- Chair-side Restorations.

- Conventional LOST-WAX technique.

Limitations of CAD/CAM systems

- Initial High Cost of CAD/CAM Systems.

- Need to Master using the technology

\section{CONCLUSION}

$\mathrm{CAD} / \mathrm{CAM}$ has been in use extensively for the past two decades, in prosthodontics. From a time where the work was restricted to the laboratory alone, now it has been used even in dental clinics facilitate chair side restorations. This technology is used to fabricate not only smaller restorations like inlays, onlays, veneers, crowns, but also larger restorations like fixed partial dentures, removable partial dentures, maxillofacial prostheses, implant abutments and full-mouth restorations. Even though the CAD/CAM systems areexpensive, the accuracy and the quality of restoration definitely outweighs the disadvantage and it is already one of the leading technologies that has changed the face of prosthodontics.

\section{References}

1. F. Beuer,1 J. Schweiger2 and D. Edelhoff. Digital dentistry: an overviewof recent developments for CAD/CAM generated restorations. British Dental Journal Volume 204 NO. 9 MAY 102008

2. P.R. Liu, M.E. EssigPanorama of dental CAD/CAM restorative systems Compend Contin Educ Dent, Volume 29, 2008, pp. 482-488

3. Duret F, Preston JD. CAD/CAM imaging in dentistry. Curr Opin Dent 1991; 1: 150-154. 
4. Mormann W.H., The origin of the cerec method: a personal review of the first 5 years. Int J Comput Dent. 2004; 7(1): 11-24.

5. Anderson $M$, oden A. A new all ceramic crown: a dense sintered, high purity alumina coping with porcelain. Acta Odontol Scand 1993; 51: 59-64.

6. Anderson M. Carlsson L, Persson M, Bergmann B. Accuracy of machine milling and sparkerosion with a CAD/CAM system. J. Prosthet Dent 1996; 76:187-93.

7. Ellingsen LA, Fasbinder DJ. An in vitro evaluation CAD/CAM ceramic crowns. J. Dent Res 2002; 81:331

8. May KB, Russel MM Razzoog ME, et al. Precession of fit; the procera all Ceram crown. J Prosthet Dent 1998; 80: 394-404.

9. Tinschert J, Natt G, Mautsch W. et al. Marginal fit of alumina and zirconia based fixed partial dentures produced by a CAD/DAM system. Oper Dent 2001; 26:367-374.

10. Liu PR. A panorama of dental CAD/CAM restorative systems. Compend Contin Educ Dent 2005: 26(7); 507512.

11. Ariko K. Evaluation of the marginal fitness of tetragonal zirconia polycrystal all ceramic restorations. Kokubyo Gakkai Zasshi 2003;70:114-123 (Japanese).
12. Hertlein G. Kramer M, Sprengart T, et al. Milling time Vs marginal fit of CAD/CAM manufactured zirconia restorations. J. Dent Res 2003; 82:194.

13. Vander Zel J, Vlaar S, Ruiter W, Davidsonc. The CICERO system for CAD/CAM fabrication of full ceramic crown. J Prosthet Dent 2001; 85:261- 67.

14. Freedman M, Quinn F, Sullivan M. Single unit CAD/DAM restorations: a literature review. J Irish Dent Assoc 2007; 53:38-45.

15. Miyazaki T, Hotta y. Kunii J, Kuriyama S and Tamaki y. A review of Dental CAD/CAM: Current status and future perspectives from 20 years of experience. Dent Mat J. 2009; 28 (1): 4456.

16. Sykes LM, Parrott AM, Owen CP et al. Applications of rapid prototyping technology in maxillofacial prosthetics. Int. J. Prosthodont 2004;17(4):454-459.

17. Bibb R, Eggbeer D, Williams RJ. Rapid manufacture of removable partial denture frameworks. Rapid Prototyping Journal 2006; 12(2):95 - 99.

18. Bibb R, Eggbeer D, Evans $\mathrm{P}$ et al. Rapid manufacture of custom-fitting surgical guides. Rapid Prototyping Journal 2009; 15(5):346 - 354.

19. Marchack CB. An immediately loaded CAD/CAMguided definitive prosthesis: A clinical report. $J$ Prosthet Dent 2005;93:8-12.

\section{How to cite this article:}

Prema Sivakumar and Preetham Prasad Nittla (2017) ' CAD/CAM In Prosthodontics: An Era of Digital Dentistry', International Journal of Current Advanced Research, 06(04), pp. 3045-3047.

DOI: http://dx.doi.org/10.24327/ijcar.2017.3047.0176 